\title{
ГУМАНИТАРНАЯ ЭКСПЕРТИЗА
}

DOI: 10.17805/zpu.2018.1.2

\section{Социогуманитарные контуры технонауки: актуальность гуманитарной экспертизы *}

\author{
Е. Г. ГРЕБЕНЩИКОВА
}

ИНСТИТУТ НАУЧНОЙ ИНФОРМАЦИИ ПО ОБЩЕСТВЕННЫМ НАУКАМ РОССИЙСКОЙ АКАДЕМИИ НАУК;

РОССИЙСКИЙ НАЦИОНАЛЬНЫЙ ИССЛЕДОВАТЕЛЬСКИЙ МЕДИЦИНСКИЙ УНИВЕРСИТЕТ

ИМ. Н. И. ПИРОГОВА

Концепция гуманитарной экспертизы, разработанная российскими исследователями (Б. Г. Юдиным, В. А. Луковым и др.), до настоящего времени не рассматривалась в контексте теоретических подходов и практических механизмов разрешения социально значимых проблем технонаучного развития, сложившихся за рубежом, а именно социальная оценка научно-технического развития (ТА); этические, правовые и социальные последствия (ELSI); этические, правовые и социальные аспекты (ELSA); ответственные исследования и инновации (RRI). Предложенная в статье попытка компаративного анализа продемонстрировала специфику гуманитарной экспертизы. Показана ее ориентация на человека и возможности гуманизации человеческих отношений как условие и предпосылка поиска взвешенных, социально приемлемых и человеко-ориентированных решений.

Были выделены общие для гуманитарной экспертизы и зарубежных концепций и подходов установки - систематичность и целенаправленность деятельности, междисциплинарный характер, развитие совещательных процедур и каналов коммуникации между наукой и обществом, опережающее реагирование, комплексный характер решаемых проблем.

Проведенный анализ подтвердил актуальность гуманитарной экспертизы. Исследование может стать первым шагом на пути ее дальнейшего развития, которое должно учитывать как опыт отечественного социогуманитарного дискурса, так и позитивные ресурсы зарубежных концепций и подходов.

Ключевые слова: гуманитарная экспертиза; технонаука; ответственные исследования; ответственные инновации; этика науки; социальная оценка техники

\section{ВВЕАЕНИЕ}

C тремительное развитие науки и технологий сопровождает не только оптимизм и ожидания прозелитов технобудущего, но и опасения относительно возможных рисков, негативных последствий и неопределенных перспектив для человека и общества. Необходимость целенаправленной и систематический деятельности по оценке, анализу и разрешению сложных коллизий, порожденных научно-техниче-

* Работа выполнена по гранту РНФ № 15-18-10013.

The study was supported by the Grant of Russian Science Foundation, project No. 15-18-10013. 
ским прогрессом, была осознана во второй половине прошлого века. В этот период возникли биоэтика и социальная оценка техники, оказавшие в конце XX в. влияние на формирование американской ELSI-программы (Ethical, Legal, and Social Implications) в проекте «Геном человека», а затем европейских подходов ELSA (Ethical, Legal, and Social Implications) и RRI (Responsible Research and Innovation). Способы рассмотрения и механизмы решения проблем, сложившиеся в рамках этих программ и подходов, позволили пересмотреть роль социально-гуманитарного знания в процессах научно-технического развития, а также взаимоотношения между технонаукой, обществом и структурами, принимающими решения.

Гуманитарная экспертиза, теоретически разработанная такими российскими авторами, как Б. Г. Юдин, И. И. Ашмарин, В. А. Ауков, Г. Б. Степанова и др., и успешно реализованная в ряде проектов и мероприятий (Человеческий потенциал, 1999), может рассматриваться как отечественный вариант социогуманитарного сопровождения технонаучных проектов. Однако вопрос о релевантности концептуальных установок, методологических инструментов и практических механизмов, сложившихся в России и за рубежом, до настоящего времени оставался открытым. Ответом на него может стать компаративный анализ как предпосылок, к которым относятся биоэтика и социальная оценка этики, так и основных подходов оценки этических, правовых и социальных последствий и аспектов крупных технонаучных проектов и «ответственных исследований и инноваций», развитие которых нередко рассматривается в логике ELSI-ELSA-RRI.

\section{СОЦИААЬНАЯ ОЦЕНКА ТЕХНИКИ}

В отличие от биоэтики, которая в России институционализирована в деятельности этических комитетов, введена в практику преподавания и развивается как исследовательское направление, социальная оценка техники ни в теоретическом, ни в практическом плане такого широкого признания не получила.

Социальная оценка техники сформировалась в 1960-е годы в Северной Америке в ходе парламентских консультаций по поводу развития техники. В 1972 г. был подписан закон об оценке техники и создано Бюро при Конгрессе США, в задачи которого входило обеспечение сенаторов и конгрессменов объективной информацией в данной области с целью раннего предупреждения негативных последствий техники. В то же время в самом Конгрессе США был создан Совет по оценке техники (Technology Assessment Board). После его закрытия в 1995 г. приоритет в развитии этого направления оказался за западноевропейскими исследователями (Горохов, 2011: 6-9).

Один из ведущих теоретиков социальной оценки техники А. Грунвальд видит ее основную задачу в решении проблемы социальной проектируемости техники, дружественной обществу, человеку и окружающей его природе (Грунвальд, 2011a). Он обращает внимание на необходимость междисциплинарной методологии и выделяет следующие этапы: 1) обнаружение механизмов, исходящих от техники воздействий на окружающую среду и общество; 2) изучение обратного действия этих эффектов на человеческую индивидуальную и коллективную деятельность; 3) изучение и рефлексия механизмов технического развития и его влияния в различных общественных сферах, равно как и обнаружение факторов его влияния на зависимость технического развития от политических и общественных граничных условий 
и констелляций потребностей; 4) подготовка на основе полученных знаний способов действия, обеспечивающих овладение проблемой (Грунвальд, 2011b: 71-72).

Важной особенностью социальной оценки научно-технического развития является ее проблемная ориентация, которая задается контекстами производства знания. «Задача проблемно ориентированного исследования техники формулируется, в первую очередь не с внутринаучной точки зрения, а основывается на социальных ожиданиях. $<$... $>$ Проблемно ориентированное исследование не может ждать, когда будут выяснены фундаментальные основания данной исследовательской области, чтобы затем на базе хорошо проверенной теории собрать данные и выработать предложения. Напротив, оно должно даже при неясном теоретическом базисе попытаться на основании научных методов достаточно гибко и аргументированно представить решение» (Бехманн, 2010: 139). Таким образом, социальные ожидания, а также потребности и ценности определяют условия диалога сторон, заинтересованных в решении проблемы.

Оценку техники нередко критиковали за ретроспективный подход, однако предвидение эффектов развития технологий также предполагает анализ возможных будущих последствий и вместе с тем признание неполноты и недостоверности имеющегося знания, «что обязывает к ясному раскрытию условий его пригодности». Рассматривая специфику социальной оценки техники, А. Грунвальд пишет: «Такого рода оценка должна... попытаться указать на ошибки и исправить неверные оценки, а такие понятия, как обратимость и терпимость к ошибкам, приобретают новое значение» (Грунвальд, 2011а: Электронный ресурс).

Социальная оценка техники сложилась как современный тип междисциплинарных научных исследований, она институционализирована в различных структурах на национальном и международном уровнях; уже накоплен пусть не большой, но успешный опыт реализации образовательных программ или преподавания (Горохов, Грунвальд, 2011: 144).

«ЕLSI-ФИКАЦИЯ» ТЕХНОНАУКИ:

ОТ ПРОЕКТА «ГЕНОМ ЧЕАОВЕКА» К РАМОЧНЫМ ПРОГРАММАМ ЕС

Проект «Геном человека» - самый масштабный биотехнологический проект, с которым связан «амбициозный эксперимент», объединивший финансирование научных исследований и их этических, социальных и юридических последствий (Ethical, Legal, and Social Implications). ELSI-программа была предложена первым директором проекта - нобелевским лауреатом Аж. Уотсоном. «Таким образом, помимо открытия структуры AHK вместе с Фрэнсисом Криком, Уотсону также можно приписывать “изобретение” ELSA и придание импульса тому, что получило название "Elsi-фикация": интеграция социальных исследований в крупномасштабные техно-научные программы» (Zwart, Nelis, 2009: 540). Программу нередко называют самым дорогостоящим проектом в истории биоэтики, поскольку с момента начала в 1990 г. на нее выделялось от 3 до $5 \%$ от всего финансирования проекта «Геном человека».

На первом этапе она была нацелена на решение следующих задач: 1) предвидеть и рассмотреть социальные последствия картирования и секвенирования генома человека; 2) изучить этические, правовые и социальные последствия картирования и секвенирования генома человека; 3) стимулировать общественное обсуждение во- 
просов; разработать варианты политики, гарантирующие, что информация будет использоваться в интересах общества (ELSI Planning: Электронный ресурс). В настоящее время выделены следующие приоритеты программы: психосоциальные и этические проблемы в исследованиях геномики; психосоциальные и этические проблемы в геномной медицине; вопросы правовой и государственной политики; более широкие социальные проблемы (McEwenet al., 2014: 484).

В данном контексте важно отметить, что программа охватывала только проблематику исследований генома человека. В результате были рассмотрены как традиционные (например, информированное согласие и конфиденциальность), так и вновь возникающие (например, концептуализация и распространение генетической информации под растущим влиянием социальных сетей) проблемы биоэтики. Кроме того, исследования оказали влияние на клиническую практику. Так, работа исследовательского консорциума ELSI по муковисцидозу стала основой для разработки профессиональных руководящих принципов, лабораторных стандартов и материалов для обучения и информированного согласия.

Вопрос о влиянии программы на социальные контексты и принимаемые политические решения является дискуссионным, поскольку выявить непосредственное воздействие фундаментальных исследований на практику довольно сложно, как и проблематично отследить их прямое влияние на руководства, акты и социальную политику в области генетики (там же). Тем не менее влияние программы можно проследить в области практики и политики, связанных с исследованиями в сфере геномики и геномной медицины, а также в более широком контексте социальной политики.

Несмотря на довольно острую критику, программа исследования этических, социальных и юридических последствий картирования и секвенирования генома человека признана успешной. Она продемонстрировала возможность эффективного взаимодействия специалистов разных областей знания в решении биоэтических проблем и обеспечения открытости и доступности преимуществ исследований генома человека для общества.

\section{ЭТИЧЕСКИЕ, ЮРИАИЧЕСКИЕ И СОЦИААЬНЫЕ АСПЕКТЫ}

\section{РАЗВИТИЯ НОВЫХ ТЕХНОНАУЧНЫХ ПРОЕКТОВ}

В отличие американской программы, ELSA-инициатива (A-aspects), предложенная в Канаде, Европе и ряде других стран, изначально ориентировалась на широкий круг проблем, возникающих в новых областях технонауки. На уровне Европейского союза она была представлена впервые в Четвертой рамочной программе. Национальные ELSA-инициативы в Австрии, Нидерландах и Великобритании сформировались в конце 1990-х годов только в сфере наук о жизни, что повлияло на их восприятие как тесно связанных с биотехнологиями (Hilgartner, Prainsack, Hurlbut, 2017: 823-851).

Важной характеристикой ELSA-подхода является не только более широкий охват проблем современного технонаучного развития, но и большее внимание к социальным контекстам производства знаний, активное включение общества в обсуждение повестки научных исследований, ориентация на меж- и трансдициплинарные подходы, стремление предвосхищать и предупреждать различные эффекты, насколько это возможно, для разработки стратегий «мягкого» управления. Задавая 
общие ориентиры, ELSA-инициатива не ограничивается какой-то единой методологией или практикой рассмотрения и решения проблем. Ее принципиальной установкой является идея о том, что наука развивается в обществе, находится под его влиянием и, в свою очередь, оказывает влияние на него. Поэтому эффективное развитие технологических инноваций предполагает подотчетность науки и учет социальных контекстов ее развития. Эти установки унаследовал подход «Ответственные исследования и инновации» (Responsible Research and Innovation, RRI).

\section{ОТВЕТСТВЕННЫЕ ИССАЕАОВАНИЯ И ИННОВАЦИИ}

Ответственные исследования и инновации - прозрачный интерактивный процесс, благодаря которому социальные акторы и инноваторы принимают на себя взаимную ответственность с точки зрения (этической) приемлемости, устойчивости и общественной желательности инновационного процесса и его товарных продуктов (для обеспечения правильного внедрения научно-технических достижений в обществе) (Von Schomberg, 2011: Электронный ресурс).

Термин «ответственное исследование» впервые появился в Шестой рамочной программе, где ответственное исследование и применение науки и техники подразумевало взаимодействие между различными организациями и видами деятельности, которое должно способствовать диалогу в глобальном контексте, а также развитию исследований в области этики науки и техники. Термин «ответственное исследование и инновация» первоначально был использован в Седьмой рамочной программе, а затем в программе «Горизонт $2020 »$, где основное внимание было уделено сотрудничеству между наукой и обществом, укреплению общественного доверия к науке (Burget, Bardone, Pedaste, 2017). В последние годы этот подход приобрел большее значение в Европе, став предметом активных научных дискуссий. Эволюция RRI-подхода большинством авторов рассматривается в логике перехода от ELSI к ELSA, а затем к RRI с учетом того вклада, который внесли биоэтика, социальная оценка техники и исследования науки и технологий (STS) (Zwart, Landeweerd, van Rooij, 2014).

Специфику RRI-подхода определяют следующие черты: антиципация, инклюзия, рефлексивность и реагирование (Burget, Bardone, Pedaste, 2017).

Антииипачия (англ. anticipation - предвосхищение, ожидание) позволяет понять, каким образом текущая динамика влияет на проектирование будущего. Она направлена на раннее предвидение и предотвращение потенциально опасных последствий новых технологий и нацелена: 1) на рефлексию мотивов и последствий исследовательского проекта; 2) прояснение неопределенностей и дилемм; 3) раскрытие образов будущего для широкой публики; 4) использование результатов для выбора направлений развития исследований и инноваций. Антиципацию нельзя понимать только как попытку предвидения, это прежде всего стратегия выбора устойчивых траекторий и привлечения ресурсов, необходимых для достижения социально приемлемых и желательных образов будущего.

Инклюзия предполагает активное привлечение различных заинтересованных сторон, в том числе на самых ранних стадиях исследований и инноваций. Формы включения заинтересованных социальных акторов могут быть различными: консенсусные конференции, научные семинары, жюри и панели граждан, фокус-группы и др. Реагирование на риски новых технологий может иметь разную временную 
перспективу (среднесрочную, долгосрочную) и касаться разных сторон жизнедеятельности общества.

Рефлексивность ориентирована на диалог и взаимные ожидания между наукой и обществом, отражение ценностей и убеждений в исследованиях и разработках. Она может способствовать лучшему пониманию учеными этических и социальных аспектов их работы, а также предупреждению рисков ошибочных решений на ранних стадиях, что связывает рефлексивность с антиципацией.

В целом ответственные исследования и инновации нацелены на достижение социальной или экологической пользы; постоянное вовлечение общества, включая общественные и неправительственные группы, на всех этапах инновационного процесса; взвешенную оценку актуальных и возможных социальных, этических и экологических коллизий, рисков; способность контролирующих структур принимать эффективные управленческие решения и быстро адаптироваться к изменяющимся знаниям и обстоятельствам; обеспечение открытости научно-инновационного процесса (Sutcliffe, 2011: Электронный ресурс).

\section{ГУМАНИТАРНАЯ ЭКСПЕРТИЗА И СОЦИОГУМАНИТАРНЫЕ КОНТУРЫ ТЕХНОНАУКИ}

Гуманитарная экспертиза, предложенная отечественными учеными, в полной мере вписывается в контекст сложившихся к настоящему времени подходов, нацеленных на анализ и оценку позитивных и негативных эффектов технонаучных инноваций для человека и общества. Однако если социальная оценка техники, ELSпрограммы и RRI-подход особое внимание уделяют социальным измерениям, то гуманитарная экспертиза фокусируется прежде всего на человеке, его интересах и возможностях. Кроме того, Б. Г. Юдин и Вал. А. Ауков отмечают: «...прилагательное “гуманитарная" в ее названии имеет не только тот смысл, что речь идет о человеке и человеческом, но и о ее возможностях в смысле гуманизации человеческих взаимоотношений и взаимодействий, об особом типе этих взаимоотношений и взаимодействий. С этой точки зрения мы обнаруживаем, что результат гуманитарной экспертизы никоим образом не ограничивается итоговым заключением, к которому пришла группа экспертов. Не менее важен и еще один результат - установление каналов, по которым и в дальнейшем может осуществляться взаимодействие, и формирование самих участников әтого взаимодействия, осознающих и умеющих использовать его конструктивные возможности» (Юдин, Ауков, 2008: 29). Последнее утверждение в некотором смысле сближает отечественную концепцию и зарубежные подходы, нацеленные на активное развитие совещательньх процедур и различных каналов коммуникации между наукой и обществом. Разработчики гуманитарной экспертизы подчеркивают ее принципиально неокончательный характер. Основной целью во многих случаях является не конкретное решение, которое нередко чрезвычайно трудно найти, а процедура согласования интересов всех сторон. Таким образом, процессуальный характер имеет значение для развития конструктивных связей, навыков взаимодействия и совместного поиска решений на благо человека, что рассматривается как фактор гуманизации человеческих взаимоотношений.

Как гуманитарная әкспертиза, так и зарубежные подходы предполагают систематическую деятельность, а не одноразовые мероприятия, которые могут быть 
реализованы в разных форматах. Теоретические основания гуманитарной экспертизы, по сути, могут служить методологическими ориентирами для различных экспертных процедур, но выбор конкретной формы определяется инициаторами, экспертами и спецификой проблемы. В этом ракурсе опыт зарубежных мероприятий разного уровня может быть востребован и полезен.

Источниками гуманитарной экспертизы являются как научный прогресс, порождающий технологические инновации, так и социальная практика, с которой связно возникновение новых социальных технологий. Таким образом, еще одной чертой, специфицирующей гуманитарную экспертизу, является ее нацеленность на комплексные проблемы, которые не ограничиваются сферой биомедицины (как ELSI) или областью технических инноваций (как социальная оценка техники). Решение этих проблем предполагает объединение теоретических перспектив разных дисциплин, а потому междисииплинарность - еще одна особенность, характерная Аля всех рассматриваемых концепций и практик.

Идея опережаюшего реагирования, фундирующая основные установки гуманитарной экспертизы, коррелирует с ориентацией на антиципацию и превентивные стратегии, которые явным образом выражены в ELSA-программе и RRI-подходе, но также важны и для социальной оценки техники и ELSI-программы. Отечественные исследователи подчеркивают, что это позволит предотвратить или внести коррективы до того момента, когда со стороны общества могут потребоваться значительные усилия. Зарубежные авторы обращают внимание на более широкие факторы антиципации, включая экономические и политические аспекты социальной акцептации инноваций, возможные и желаемые сценарии будущего, предвосхищение новых областей, представляющих интерес для инвестирования имеющихся ресурсов, а также лучших вариантов выбора из доступных возможностей (Tutton, 2011: 411-429).

\section{ЗАКАЮЧЕНИЕ}

Успешный опыт реализации проектов по социальной оценке техники, исследованию социальных, правовых и этических последствий и аспектов развития технонаучных проектов в разных сферах жизнедеятельности общества, а также подхода «ответственные исследования и инновации» на уровне рамочных программ Евросоюза подтверждает необходимость целенаправленной и систематической деятельности по оценке и анализу тех позитивных и негативных эффектов, которые порождает современная наука и технологии. В такой перспективе гуманитарная экспертиза, нацеленная не только на технологические инновации, но и на социальные технологии, имеет особую актуальность. Основанная на идеях опережающего реагирования, комплексном междисциплинарном подходе и совещательных процедурах, она в полной мере вписывается в социогуманитарные контуры современной технонауки. Вместе с тем фокус на человеке и его возможностях позволяет говорить о специфике отечественного подхода, который является условием и предпосылкой поиска взвешенных, социально приемлемых и человеко-ориентированных решений. Проведенный анализ, подтверждая актуальность гуманитарной экспертизы (Юдин, 2008: 146-154), может стать первым шагом на пути ее дальнейшего развития, учитывающего опыт как отечественного социогуманитарного дискурса, так и зарубежных концепций и подходов. 
СПИСОК АИТЕРАТУРЫ

Бехманн, Г. (2010) Современное общество: общество риска, информационное общество, общество знаний. М. : Аогос. 248 с.

Горохов, В. Г. (2011) От редактора перевода // Грунвальд, А. Техника и общество: западноевропейский опыт исследования социальных последствий научно-технического развития. М. : Могос. 160 с. С. $6-9$.

Грунвальд, А. (2011а) Роль социально-гуманитарного познания в междисциплинарной оценке научно-технического развития [Электронный ресурс] // Гуманитарные технологии. Аналитический портал. URL: http://gtmarket.ru/laboratory/expertize/5371 (дата обращения: 24.10.2017).

Грунвальд, А. (2011b) Техника и общество: западноевропейский опыт исследования социальных последствий научно-технического развития. М. : Аогос. 160 с.

Горохов, В. Г., Грунвальд, А. (2011) Каждая инновация имеет социальный характер (Социальная оценка техники как прикладная философия техники) // Высшее образование в России. № 5. C. 135-145.

Человеческий потенциал: опыт комплексного подхода / под ред. И. Т. Фролова. (1999) М. : Эдиториал УРСС. 176 с.

Юдин, Б. Г. (2008) Технонаука, человек, общество: актуальность гуманитарной экспертизы // Век глобализации. № 2. С. 146-154.

Юдин, Б. Г., Ауков, Вал. А. (2008) Гуманитарная экспертиза: К обоснованию исследовательского проекта. М. : ИзА-во Моск. гуманит. ун-та. 38 с.

Burget, M., Bardone, E., Pedaste, M. (2017) Definitions and conceptual dimensions of responsible research and innovation: A literature review // Science and engineering ethics. Vol. 23. № 1. P. 1-19.

ELSI Planning and Evaluation History [Электронный ресурс]// National Human Genome Research Institute. URL: https://www.genome.gov/10001754/elsi-planning-and-evaluation-history (дата обращения: 24.10.2017).

Hilgartner, S., Prainsack, B., Hurlbut, J. B. (2017) Ethics as Governance in Genomics and Beyond // The Handbook of Science and Technology Studies. P. 823-851.

McEwen, J. E. et al. (2014) The ethical, legal, and social implications program of the National Human Genome Research Institute: reflections on an ongoing experiment // Annual Review of Genomics and Human Genetics. Vol. 15. P. 481-505.

Sutcliffe, H. (2011) A report on responsible research and innovation [Электронный pecyрc] // European Commission. URL.: http://ec.europa.eu/research/science-society/document_library/ pdf_06/rri-report-hilary-sutcliffe_en.pdf (дата обращения: 24.10.2017).

Tutton, R. (2011) Promising pessimism: reading the futures to be avoided in biotech // Social Studies of Science. Vol. 41. № 3. P. 411-429.

Von Schomberg, R. (Ed.). (2011) Towards Responsible Research and Innovation in the Information and Communication Technologies and Security Technologies Fields. Luxembourg: Publications Office of the European Union [Электронный ресурс] // European Commission. URL: http://ec. europa.eu/research/science-society/document_library/pdf_06/mep-rapport-2011_en.pdf (дата обращения: 24.10.2017).

Zwart, H., Nelis, A. (2009) What is ELSA genomics? // EMBO reports. Vol. 10. №. 6. P. 540-544.

Zwart, H., Landeweerd, L., van Rooij, A. (2014) Adapt or perish? Assessing the recent shift in the European research funding arena from 'ELSA'to 'RRI' // Life Sciences, Society and Policy. Vol. 10. № 1. P. 1-11.

Аата поступления: 25.10.2017 2.

SOCIO-HUMANISTIC CONTOURS OF TECHNICAL SCIENCE: RELEVANCE OF HUMANITARIAN EXPERTISE

\section{E. G. GREBENSHCHIKOVA}

INSTITUTE OF SCIENTIFIC INFORMATION FOR SOCIAL SCIENCES, RUSSIAN ACADEMY OF SCIENCES;

Pirogov Russian National Research MEdical University 
The concept of humanitarian expertise, developed by Russian researchers (B. G. Yudin, V. A. Lukov, and others), has not been considered so far in the context of theoretical approaches and practical mechanisms of solving socially significant problems of sci-tech development that have emerged abroad, i.e. technology assessment (TA); ethical, legal, and social implications (ELSI); ethical, legal, and social aspects (ELSA); responsible research and innovation (RRI). The specific character of humanitarian expertise was the result of the comparative analysis proposed in the article. It shows its orientation toward the human and the possibility of humanizing human relations, as a condition and prerequisite for finding well-founded, socially acceptable and human-orientated solutions.

The paper determines characteristics common for humanitarian expertise and for foreign concepts and approaches: the systematic nature and purposefulness of activity, interdisciplinary nature, the development of deliberative procedures and channels of communication between science and society, proactive response, the complex nature of the solved problems.

The conducted analysis confirmed the relevance of humanitarian expertise. The research can be the first step on the path of its further development, which should take into account both the experience of the domestic socio-humanistic discourse and the positive resources of foreign concepts and approaches.

Keywords: humanitarian expertise; technical science; responsible research; responsible innovation; ethics of science; social assessment of technology

\section{REFERENCES}

Bechmann, G. (2010) Sovremennoe obshchestvo: obshchestvo riska, informatsionnoe obshchestvo, obshchestvo znanii. Moscow, Logos. 248 p. (In Russ.).

Gorokhov, V. G. (2011) Ot redaktora perevoda. In: Grunval'd, A. Tekbnika i obshchestvo: zapadnoevropeiskii opyt issledovaniia sotsial'nykb posledstvii nauchno-tekbnicheskogo razvitiia. Moscow, Logos. 160 p. Pp. 6-9 (In Russ.).

Grunwald, A. (2011a) Rol' sotsial'no-gumanitarnogo poznaniia v mezhdistsiplinarnoi otsenke nauchno-tekhnicheskogo razvitiia. Gumanitarnye tekbnologii. Analiticheskii portal [online] Available at: http://gtmarket.ru/laboratory/expertize/5371 (In Russ.).

Grunwald, A. (2011b) Tekbnika i obshchestvo: zapadnoevropeiskii opyt issledovaniia sotsial'nykb posledstvii nauchno-tekbnicheskogo razvitiia. Moscow, Logos. 160 p. (In Russ.).

Gorokhov, V. G. and Grunval'd, A. (2011) Kazhdaia innovatsiia imeet sotsial'nyi kharakter (Sotsial'naia otsenka tekhniki kak prikladnaia filosofiia tekhniki). Vyssbee obrazovaniev Rossii, no. 5 , pp. 135-145. (In Russ.).

Chelovecheskij potencial: opyt kompleksnogo podboda (1999). Ed. by I. T. Frolov. Moscow, Editorial URSS. 176 p. (In Russ.).

Yudin, B. G. (2008) Tekhnonauka, chelovek, obshchestvo: aktual'nost' gumanitarnoi ekspertizy. Vek globalizatsii, no. 2, pp. 146-154. (In Russ.).

Yudin, B. G. and Lukov, Val. A. (2008) Gumanitarnaia ekspertiza: K obosnovaniiu issledovatel'skogo proekta. Moscow, MosGU Publ. 38 p. (In Russ.).

Burget, M., Bardone, E. and Pedaste, M. (2017) Definitions and conceptual dimensions of responsible research and innovation: A literature review. Science and engineering ethics, vol. 23, no. 1, pp. 1-19.

ELSI Planning and Evaluation History. National Human Genome Research Institute [online] Available at: https://www.genome.gov/10001754/elsi-planning-and-evaluation-history (accessed: 24.10.2017).

Hilgartner, S., Prainsack, B. and Hurlbut, J. B. (2017) Ethics as governance in genomics and beyond. The Handbook of Science and Technology Studies. P. 823-851.

McEwen, J. E. et al. (2014) The ethical, legal, and social implications program of the National Human Genome Research Institute: reflections on an ongoing experiment. Annual Review of Genomics and Human Genetics, vol. 15, pp. 481-505.

Sutcliffe, H. (2011) A report on responsible research and innovation. European Commission [online] Available at: http://ec.europa.eu/research/science-society/document_library/pdf_06/rrireport-hilary-sutcliffe_en.pdf (accessed: 24.10 .2017$)$. 
Tutton, R. (2011) Promising pessimism: reading the futures to be avoided in biotech. Social Studies of Science, vol. 41, no. 3, pp. 411-429.

Von Schomberg, R. (Ed.). (2011). Towards Responsible Research and Innovation in the Information and Communication Technologies and Security Technologies Fields. Luxembourg: Publications Office of the European Union. European Commission [online] Available at: http://ec.europa.eu/research/science-society/document_library/pdf_06/mep-rapport-2011_en.pdf (accessed: 24.10.2017).

Zwart, H. and Nelis, A. (2009) What is ELSA genomics? EMBO reports, vol. 10, no. 6, pp. 540-544.

Zwart, H., Landeweerd, L. and van Rooij, A. (2014) Adapt or perish? Assessing the recent shift in the European research funding arena from 'ELSA'to 'RRI'. Life Sciences, Society and Policy, vol. 10, no. 1, pp. 1-11.

Submission date: 25.10.2017.

Гребенщикова Елена Георгиевна - доктор философских наук, руководитель Центра научно-информационных исследований по науке, образованию и технологиям Института научной информации по общественным наукам Российской академии наук; доцент кафедры биоэтики Российского национального исследовательского медицинского университета им. Н. И. Пирогова. Адрес: 117997, Россия, г. Москва, Нахимовский пр-т, д. 51/21. Тел.: +7 (499) 124-37-83. Эл. aspec: aika45@ya.ru

Grebenshchikova Elena Georgievna, Doctor of Philosophy, Head, Centre for Scientific and Information Research in Science, Education and Technologies, Institute of Scientific Information for Social Sciences, Russian Academy of Sciences; Associate Professor, Department of Bioethics, Pirogov Russian National Research Medical University. Postal address: 51/21 Nakhimovsky Avenu, Moscow, Russian Federation, 117997. Tel.: +7 (499) 124-37-83. E-mail: aika45@ya.ru 